\title{
Sorting and Retrieval Robotic System Controlled via Programmable Logic Controller for Library Usage
}

\author{
M.Z.A Rashid ${ }^{1}$, H.N.M Shah ${ }^{1}$, H.I Jaafar ${ }^{1}$, M.S.M Aras ${ }^{1}$ and S.K.S Nordin ${ }^{2}$ \\ ${ }^{1}$ Faculty of Electrical Engineering, \\ ${ }^{2}$ Faculty of Manufacturing Engineering \\ Universiti Teknikal Malaysia Melaka, \\ Hang Tuah Jaya, 76100 Durian Tunggal, Melaka, Malaysia. \\ zamzuri@utem.edu.my
}

\begin{abstract}
This paper presents the conceptual idea for the sorting and retrieval robotic system controlled via Programmable Logic Controller $(P L C)$. The purpose of presenting this idea is to ease the library users and librarians to sort and retrieve the books from the library's shelf. The robotic system consists of movable platform using four wheel mobile systems. At the mobile platform there are a robotic arm and gripper that can move vertically and horizontally to pick and place the books on the shelf. The system is equipped with the colour recognition sensor and Radio Frequency Identification Detector (RFID) to ensure the robot can recognize the books located on the shelf. The system starts its operation by utilizing the sensor to detect the book on the shelf and then, the system actuator will be activated, causing the mechanism arm to extend and retract to reach to the book and the gripper will grip the book. The book that is required then can be brought down and the mobile platform will move to the counter. If the books are required to be sorted out, the motor at the robotic hand will moves the arm mechanism until the sensor detect an absence of books on the book shelf. Then, the arm will extend, sorting the book at its place by release the gripper.
\end{abstract}

Keywords: Programmable Logic Controller (PLC), sorting, retrieval, mobile robot, library

\section{Introduction}

Nowadays, a lot of libraries around the world have thousands of books, academic journals, magazines and etc. that consume much time for the users and librarians to search for them. Most of the huge libraries today are equipped with library automation system which is purposely developed for the library in housekeeping operations such as books acquisition, cataloguing the books, circulation, serial controls and in house or inter-library loans operations. Library uses various methods to arrange and retrieve the books either on the shelf, out of shelf, on loans, for instance, books are sorted according to its book number, according to author's name, according to publication or versions of books etc. According to [1], the library automation are crucial to ensure the information can be disseminated in various format either print, non- print, graphical, audio-visual etc. It also can duplicate housekeeping operation which can direct to well management and retrieval of information. [2] in their paper mentioned that there are two types of automation problems; pre automation problems and post automation problems. Pre automation problem dealt with the lack of human resource 
skills while post automation problem were mostly due to insufficient fund to equip the libraries with automation system. Before a library is equipped with an automation system, every location of the librarian's workstation, patron access points, network server, internet access and building electrical system need to be analyzed. Some libraries may require minor technological upgrades, while others will require an expensive technological renovate [2]. From the views and opinion from other researchers, this paper proposes an idea to design a robotic system that capable to sort and retrieve the books from the shelf. The system is capable to arrange and grip the books from the top of the shelf where users or librarian need a stair to climb up and hold that book.

This system consists of movable platform using four wheel mobile systems. At the mobile platform there are a robotic arm and gripper that can move vertically and horizontally to pick and place the books on the shelf. The system is equipped with the colour recognition sensor and Radio Frequency Identification Detector (RFID) to ensure the robot can recognize the books located on the shelf. The system starts its operation by utilizing the sensor to detect the book on the shelf and then, the system actuator will be activated, causing the mechanism arm to extend and retract to reach to the book and the gripper will grip the book. The book that is required then can be brought down and the mobile platform will move to the counter. If the books are required to be sorted out, the motor at the robotic hand will moves the arm mechanism until the sensor detect an absence of books on the book shelf. Then, the arm will extend, sorting the book at its place by release the gripper. The objectives of this conceptual paper is to provide an overview about a simple robotic system that can be used at the library to assist users and librarians and support the current automation system which available in the library. The system also is targeted to increase smoothness of the library daily operation.

\section{Motivation}

The paper by [1] explained about the sorting method in the library which utilizing MRS algorithm. The author also compared two sorting optimization techniques that can be used in the library which are MRS and GPU Quick Sort. [3] mentioned about the usage of RFID inside the library in order to increase efficiency and improve the safety, security, productivity, accuracy and convenience. RFID is now used to check in / check out books, self-check in/out, anti-theft detection, book drop, shelf management and tagging.

[4] developed a autonomous robotic system for book manipulation inside the library and utilized vision system called as Image processing and Optical Character

Recognition (OCR) to detect and grasp the desired books on the shelf. The robot that was used inside the research was a 5DOF robot system. [5] simulated the robotic arms system that can be used to pick up object using numerical simulation inside SIMULINK/ Matlab.

[6] had designed and constructed 6-axis robot manipulator and controlled via Visual $\mathrm{C}++$.NET. By using the Visual C++.NET new users can learn how to control this robot arm quickly. [7] developed a robotic arm that attached to the wheelchair and equipped with the user friendly interface and the product was targetted to assist diabled people. The advantages of the system were; it capable to grasp books located on the upper shelf and put it on the book holder. It also can bring the book from the book holder to lower shelf. The book can be detected using two methods; book detection with stereo camera and book detection using hand camera. The motion planning for the robotic arm movement was based on Rapidly exploring Random Trees (RRT).

In another work done by [8], the researcher had developed a Robotic Proximity Queries (RPQ) package for path planning and obstacle avoidance for arm robotic system. The research done by [9]-[10] described that the implementation and utilization of Automated Material Handling Systems (AMHS) facilities can increase the library collection storing and 
handling efficiency and at the same time enhanced the productivity and performance. The author described three methods that can be used in the library which are; Compact Shelving Storage, Automated Storage and Retrieval Systems (AS/RS) and Automated Return/Sorting Systems.

According to [11], maximum benefit can be achieved by small library by small spends on return automation. However, when the automation was increased more, the benefits obtained will be lesser for small library. For larger library, the initial cost to set up automation will be quite higher but the productivity also can be increased. The automation mentioned in this report was about the whole library automation from the return machine which covered the items returned to the library by borrower till the items arranged in the library by librarian.

[12] had developed an autonomous mobile robotic library system to retrieve items from bookshelves and carry them to scanning stations located in the off-site shelving facility. The author used 5DOF robot attached to the leveling mechanism on the mobile robotic platform to grasp the books on the shelf. The research done by [13] elaborated the implementation of PLC as controller in the management system.

\section{System Design}

The mobile robot that is designed in this paper is shown in Figure 1. Figure1 illustrates the complete isometric view of the sorting and retrieval mobile system. The complete system is built by mobile robotic platform that are attached with air compressor, wheel, air tube pneumatic rod in vertical direction, power button, start and stop indicator, and gripper. Figure 2 shows the side view, front view and top view for this mobile robot system. Figure 3 depicts the gripper on the upper part of the system. The gripper has a pneumatic rod to close for grip or opens to release the object and controlled by air from air tube. Figure 4 shows the block diagram for the system with sensors, PLC controller, motors and etc.

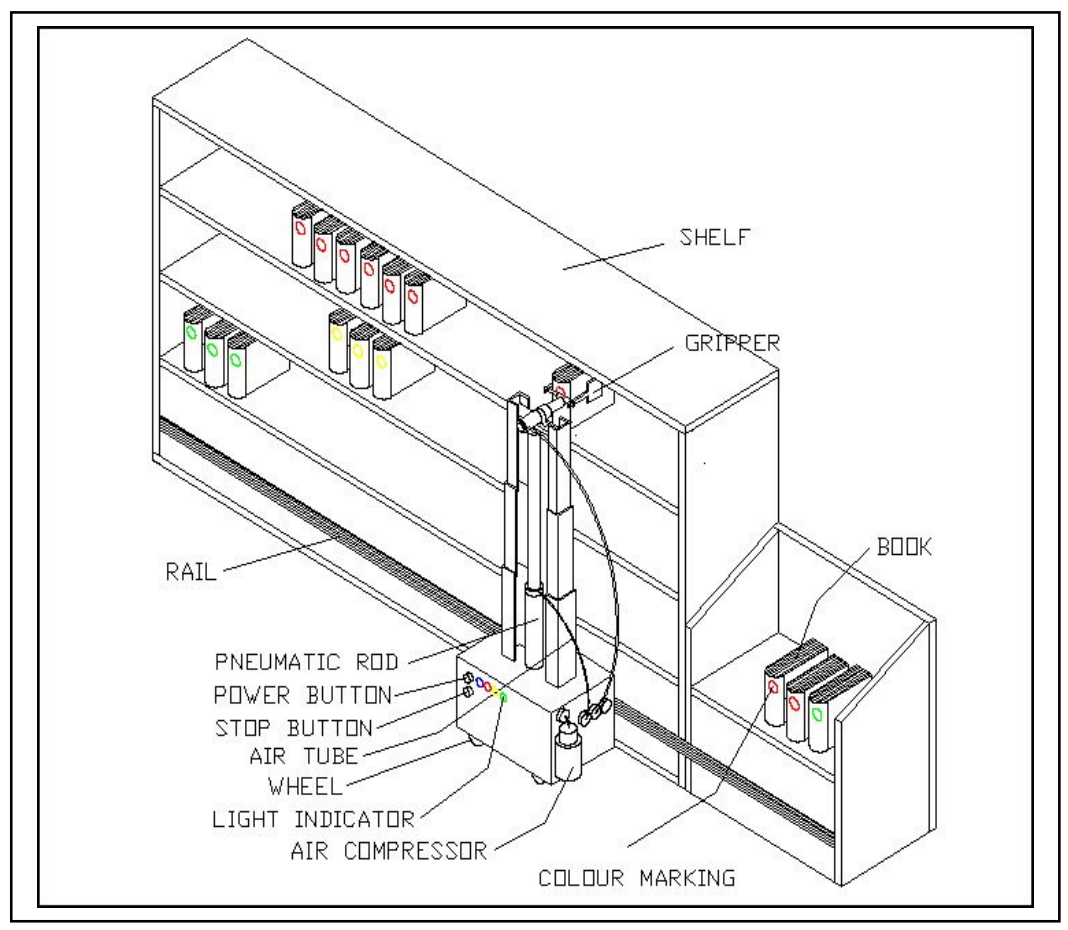

Figure 1. Isometric View of the Robot at the Library Shelf 
International Journal of $u$-and e-Services, Science and Technology Vol.7, No.4 (2014)

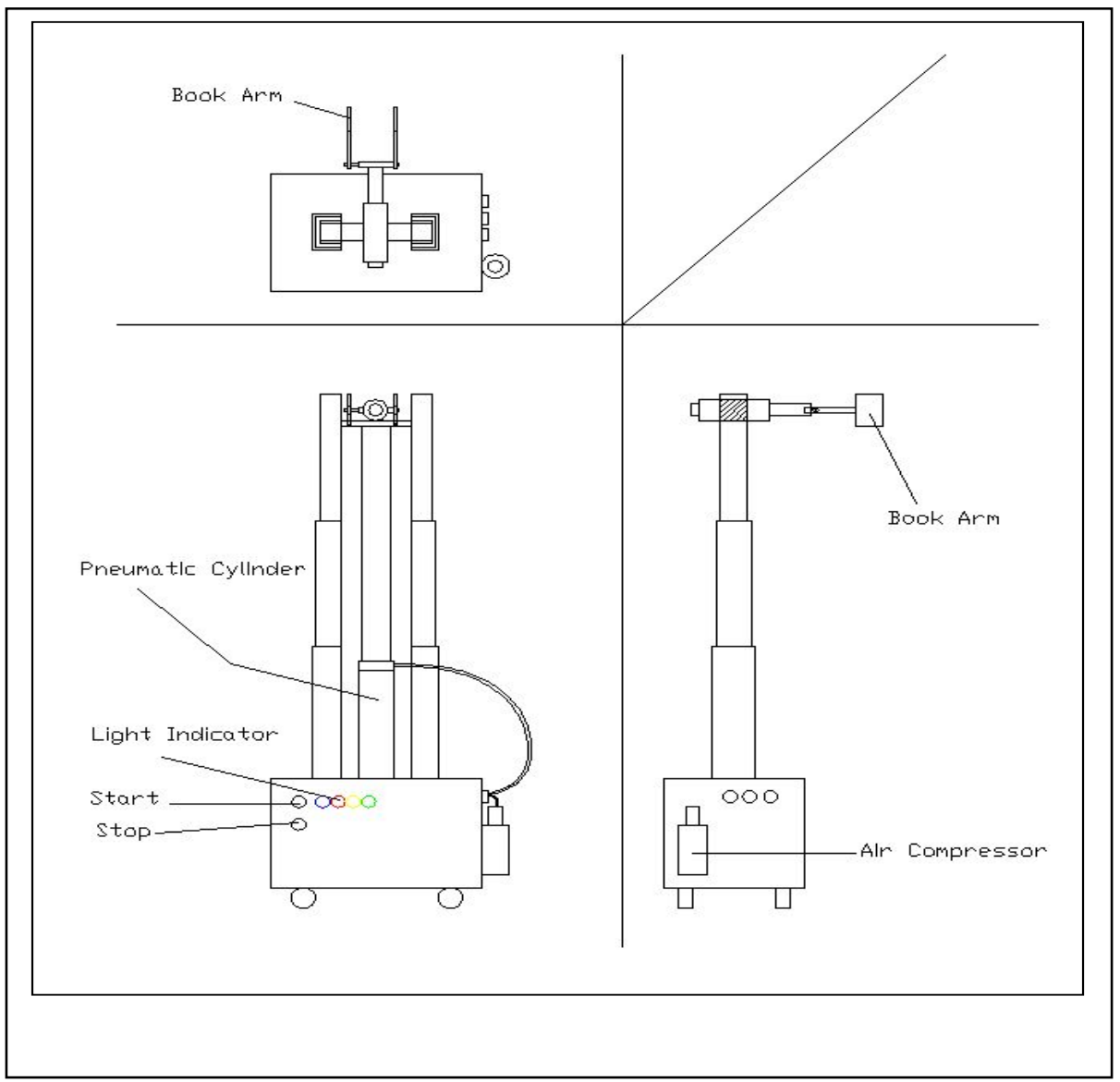

Figure 2. Side view, Front view and Top view of the Mobile Robot

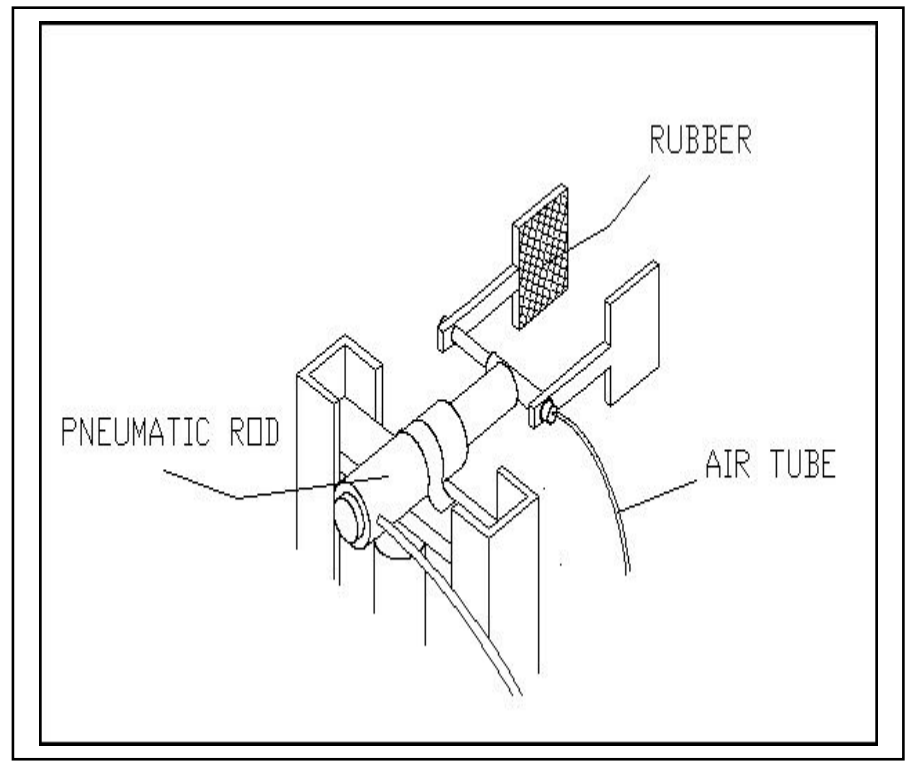

Figure 3. Isometric view of the Book's Arm Gripper at Mobile Robot 


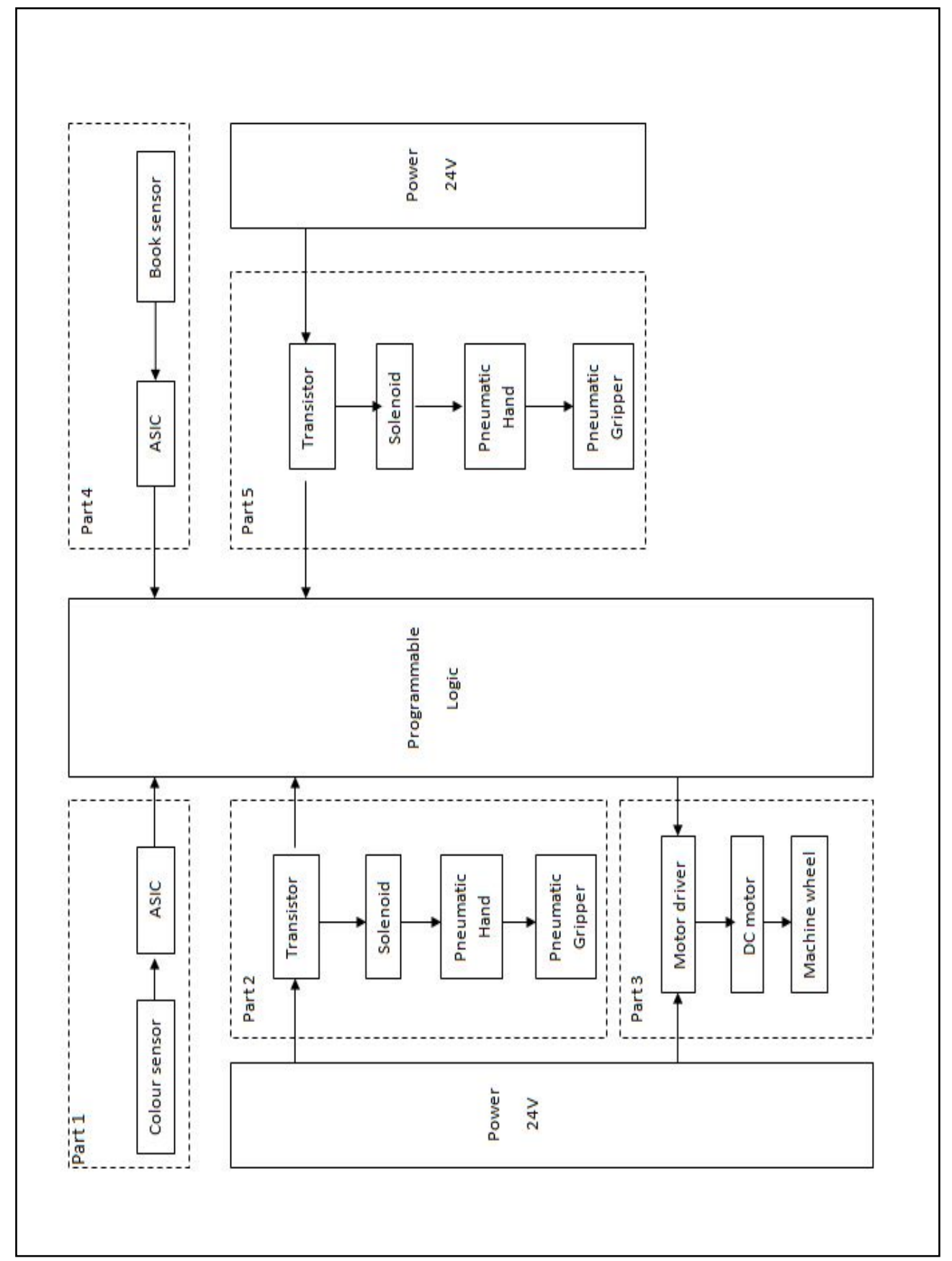

Figure 4. Isometric view of the Book's Arm Gripper at Mobile Robot

In another figure, Figure 5 elucidates the flowchart for the system to operate. Initially, the system will detect either the book available or not on the shelf and drawer inside the robot, if the sensor finds there is no book allocates on the shelf, the gripper arm will grip the books and move the book to locate either on top, middle or lower shelf based on their barcode and color. 
International Journal of u-and e-Services, Science and Technology

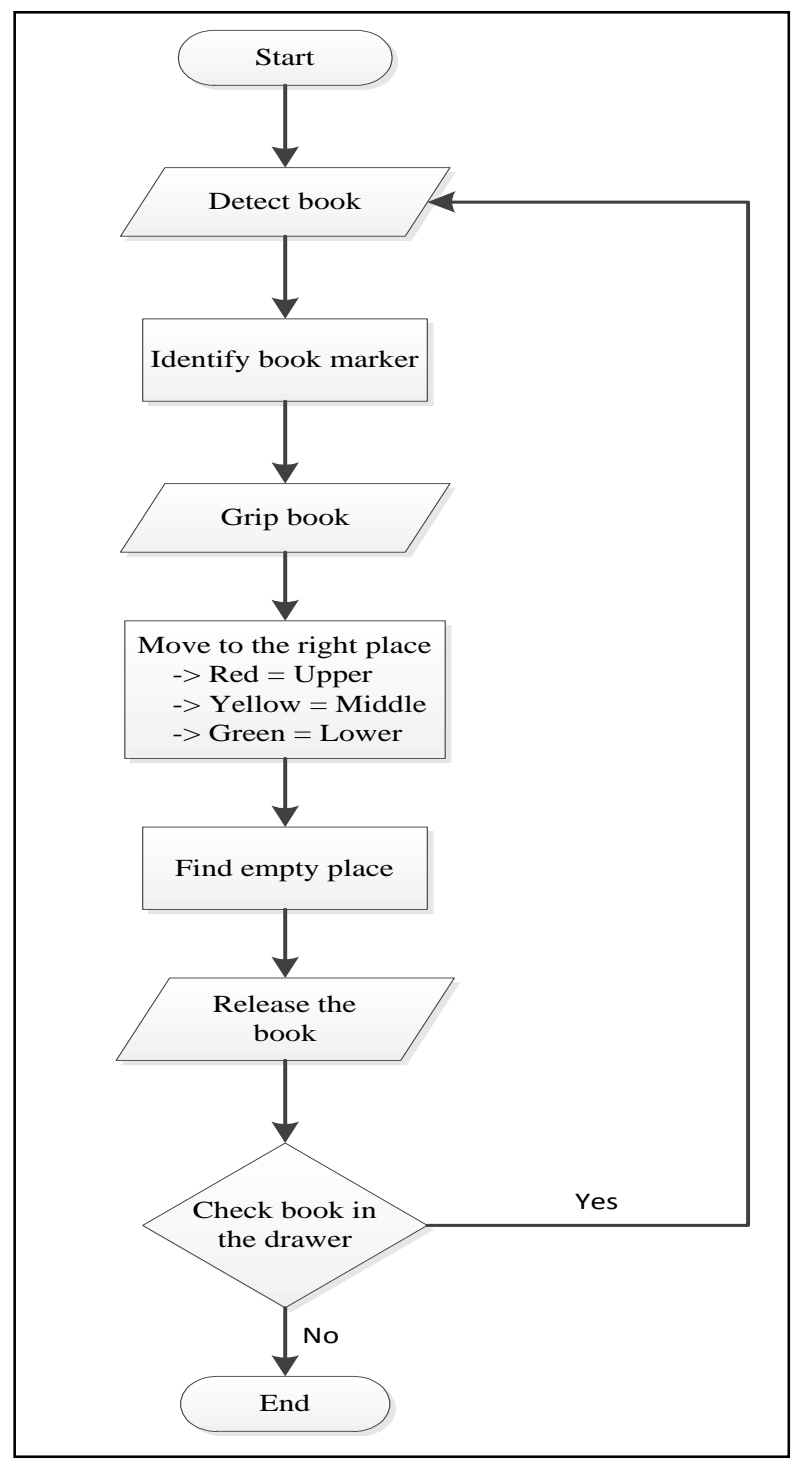

Figure 5. Process Flowchart of the Sorting and Retrieval Mobile Robot

\section{Controller and Simulation Result}

Table 1 lists the input / output that is used on the PLC port to attach the sensor, motor, pneumatic valve and etc. Another table, Table 2 shows the mnemonic codes for the PLC program to control this mobile robot system. 
Table 1. I/O Device on the PLC port

\begin{tabular}{|l|l|l|l|}
\hline INPUT & DEVICE & OUTPUT & \\
\hline 00000 & START BUTTON & 10000 & DETECT RED \\
\hline 00001 & $\begin{array}{c}\text { STOP/EMERGENCY } \\
\text { BUTTON }\end{array}$ & 10001 & $\begin{array}{c}\text { DETECT } \\
\text { YELLOW }\end{array}$ \\
\hline 00002 & RED SENSOR & 10002 & DETECT GREEN \\
\hline 00003 & YELLOW SENSOR & 10004 & GRIP LIGHT \\
\hline 00004 & GREEN SENSOR & 10015 & POWER LIGHT \\
\hline 00005 & SPACE SENSOR & & \\
\hline
\end{tabular}

Table 2. Mnemonic Code for PLC Control

\begin{tabular}{|l|l|l|}
\hline Address & Instruction & Data \\
\hline 0001 & LD & 00000 \\
\hline 0002 & OR & 10015 \\
\hline 0003 & AND NOT & 00001 \\
\hline 0004 & OUT & 10015 \\
\hline 0005 & LD & 10015 \\
\hline 0006 & AND NOT & TIM001 \\
\hline 0007 & AND & 00002 \\
\hline 0008 & OUT & 10000 \\
\hline 0009 & LD & 10015 \\
\hline 0010 & AND NOT & TIM001 \\
\hline 0011 & AND & 00003 \\
\hline 0012 & OUT & 10001 \\
\hline 0013 & LD & 10015 \\
\hline 0014 & AND NOT & TIM001 \\
\hline 0015 & AND & 00004 \\
\hline 0016 & OUT & 10002 \\
\hline 0017 & LD & 10000 \\
\hline 0018 & OR & 10001 \\
\hline 0019 & OR & 10002 \\
\hline 0020 & AND & TIM000 \\
\hline 0021 & AND NOT & TIM001 \\
\hline 0022 & OUT & 10004 \\
\hline 0023 & LD & 10015 \\
\hline 0024 & AND & 00005 \\
\hline 0025 & TIM & 001 \\
\hline 0026 & LD & 10020 \\
\hline 0027 & OR & 10000 \\
\hline 0028 & OR & 10001 \\
\hline 0029 & TIM & 000 \\
\hline & & \\
\hline & & \\
\hline
\end{tabular}


Figure 6, Figure 7, Figure 8, Figure 9 and Figure 10 show the ladder diagrams and simulation of the ladder diagram using the OMRON CX Programmer. Based on the mnemonic code and the ladder diagram in the Figure 6 - Figure 10, data 00000 is used as push-button switch while 00001 is used as stop or emergency switch. When the push-button is turn ON, light 10015 is turn ON to indicate the system is running. 10015 are also used as the contactor to the other function. To detect the book marking (red, yellow, green), light sensor is used and represented by 00002 (sensor 1), 00003 (sensor 2), 00004 (sensor 3). 00002 is used to detect red colour, 00003 for yellow colour while 00004 for green colour.

Since there is different colour marking, light indicator is used for each colour so that user can easily monitor the system. 10000 is used to indicate red marking, 10001 for yellow while 10002 for green. After the sensor detects the colour, timer (TIM000) will energized for 2 seconds and turn TIM000 timer contact to Close-Contact (NC) and energized the 10004 coil. When the coil 10004 is energized, that means the mechanism arm has gripped the book. After the infrared sensor (00005) gets the empty place, the arm mechanism will extend and place the book.

The arm mechanism will release the book gripper that takes time about 2 seconds. This means another timer is used to control the process (TIM001). The TIM001 will energize after sensor 00005 turn ON and change TIM001 timer contact to Open-Contact (OC). After 2 seconds, pneumatic arm will retract back. The colour and gripped indicator will turn OFF and the mechanism repeats all the process again.

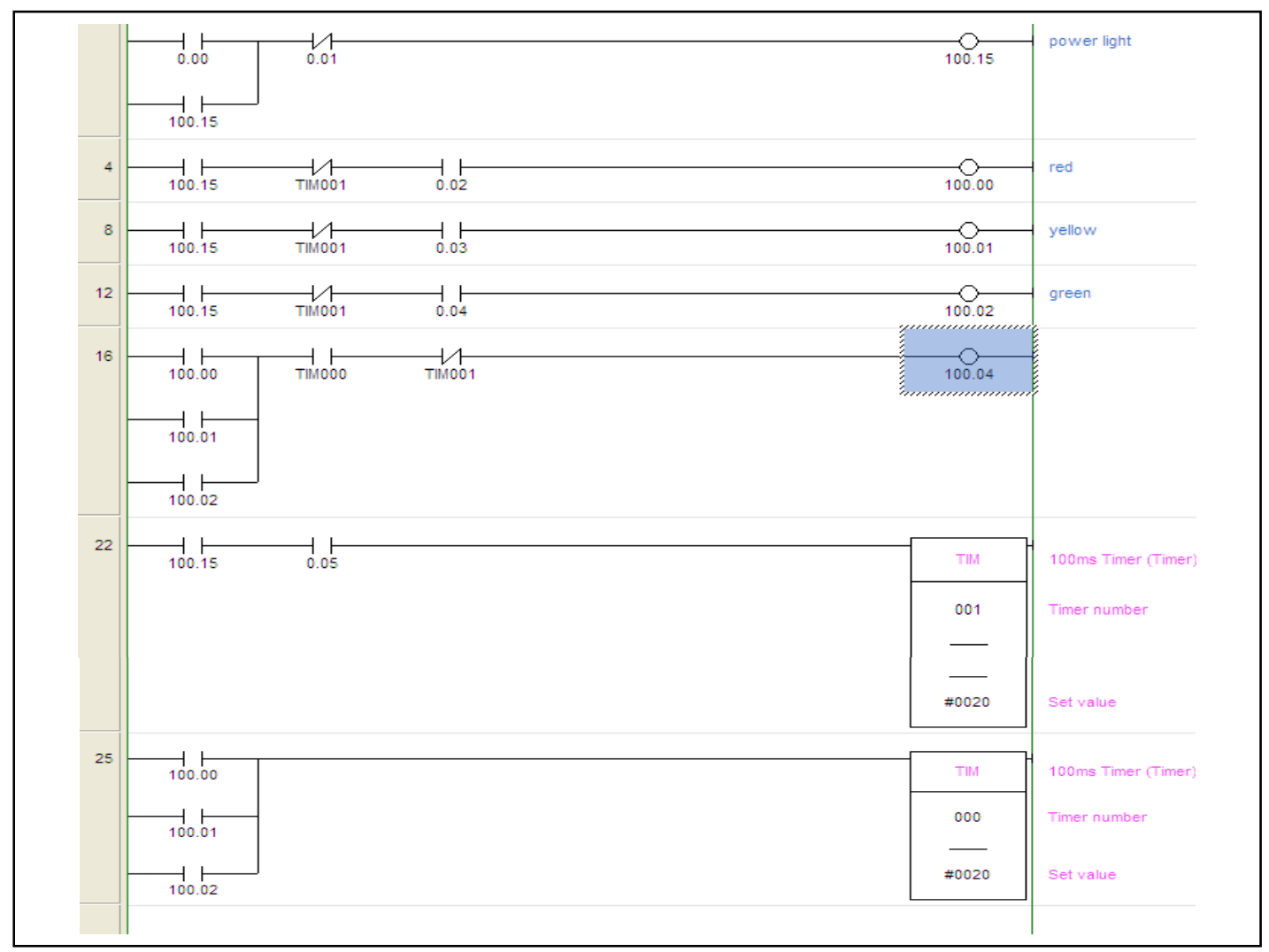

Figure 6. Ladder Diagram for the PLC Program to Control Sorting and Retrieval Mobile Robot System in Library 
ASIC is to convert the signal that can be read by programmable logic. The part 2 is function to control the all the arm mechanism that using pneumatic system which is pneumatic hand and pneumatic gripper. The transistor is used to amplify the electrical power and solenoid is used to converts electrical energy to pneumatic energy. The pneumatic robot hand is used to reach the book when it extend and followed by pneumatic gripper to grip the book. Part 3 is to control the movement of the robot. The motor driver is used to start and stop the DC motor. DC motor is function as wheel to move the robot when it finds the empty place. In part 4 , book sensor (infrared sensor) is to detect the empty place in the shelf and the function of ASIC is to convert the signal that can be read by programmable logic. Part 5 is to control the arm mechanism so that it can place the book in the shelf. When the robot gets the empty place, the pneumatic hand will extend again and followed by the pneumatic gripper to place the book.

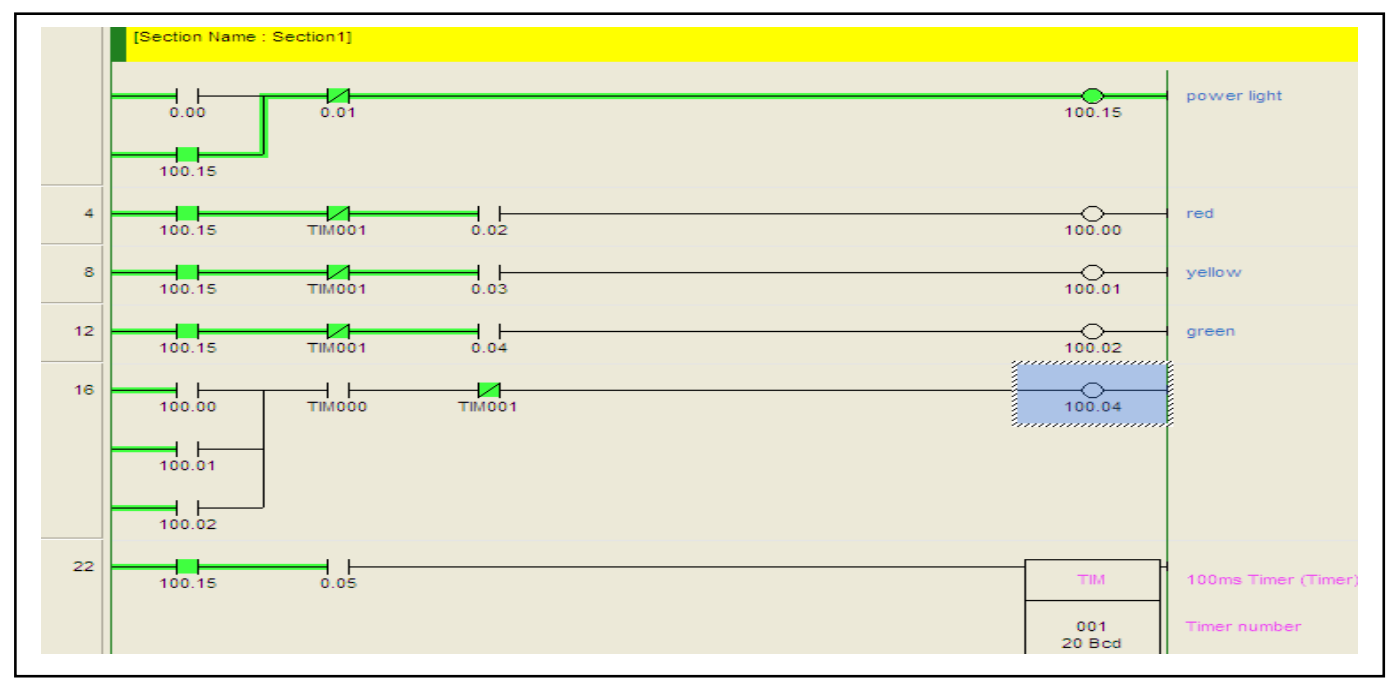

Figure 7. PLC Ladder Diagram Simulation before Books with certain Colours are Detected

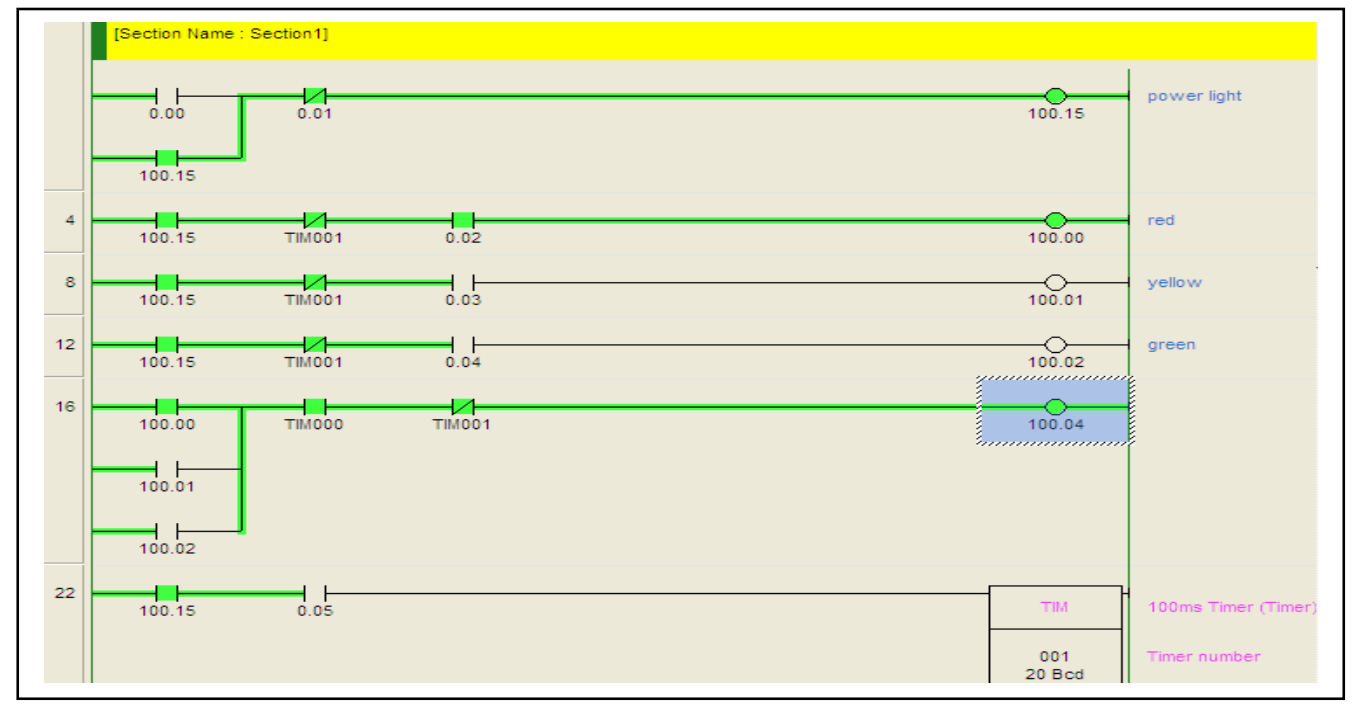

Figure 8. Arm Control 


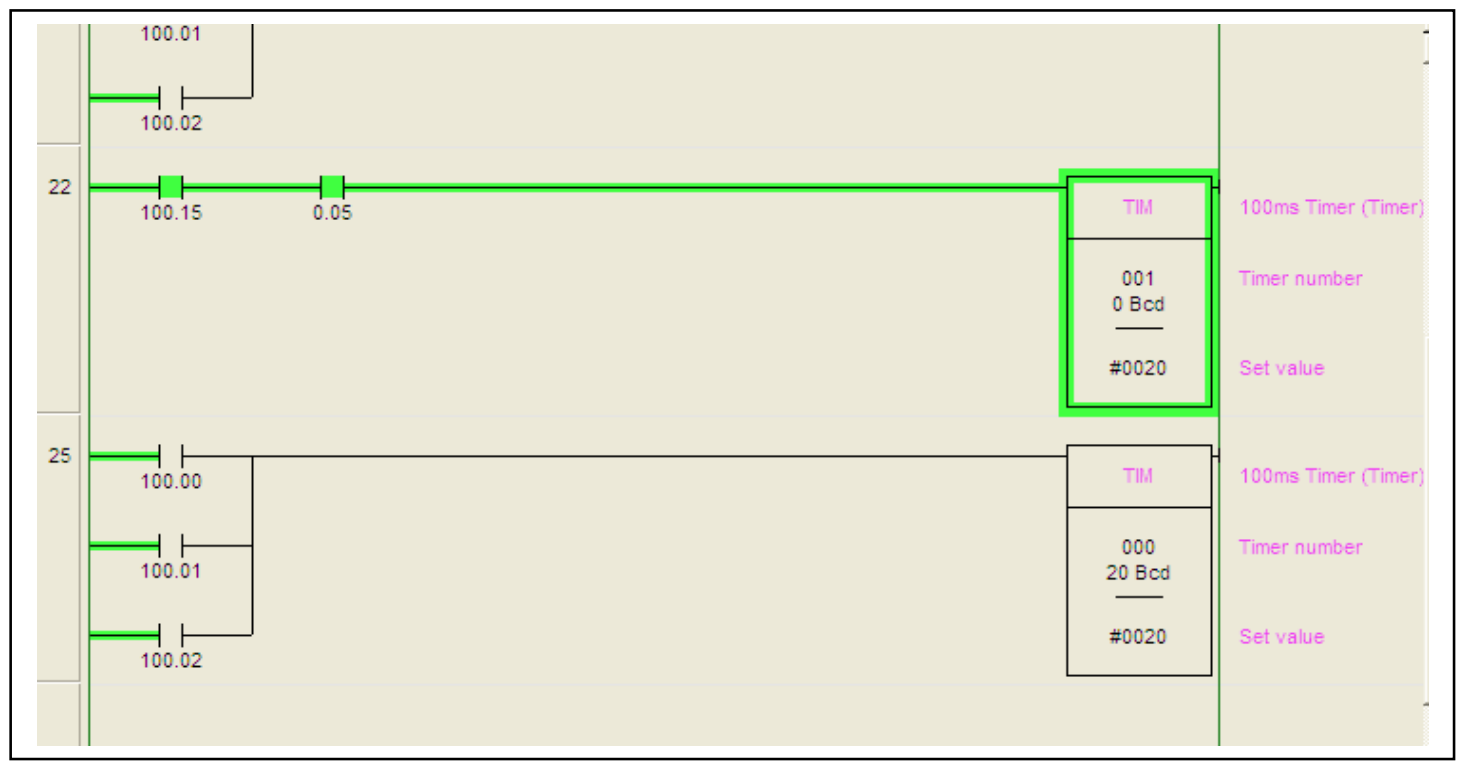

Figure 9. The Gripper Requires 2 Seconds to Grip the Book after Detecting it

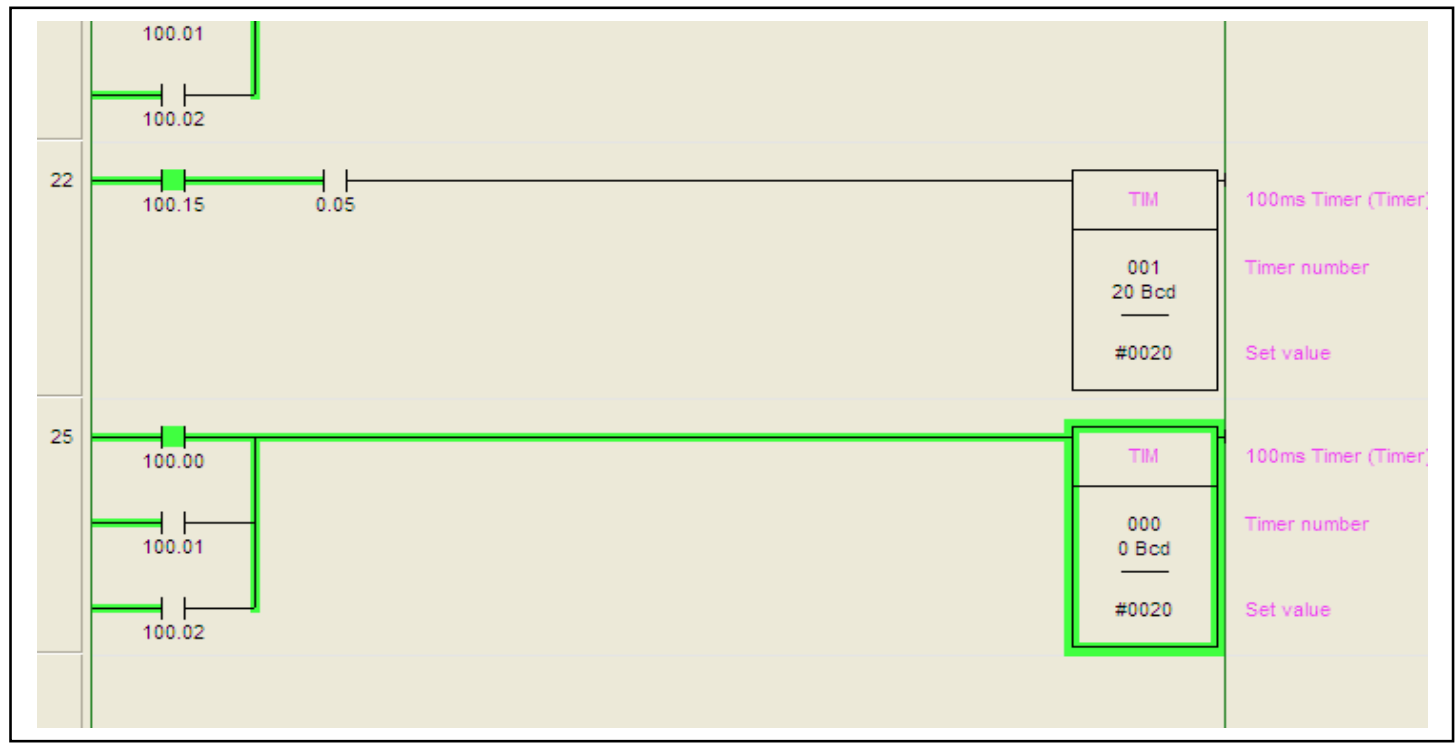

\section{Figure 10. The Gripper Requires 2 Seconds to Release the Book After Obtaining the Empty Place}

From the ladder diagram that we had constructed, our programmed run as instructed. Firstly, book sensor detects book and its colour to run. As the colour detected, the air compressor supply air and extend the arm. The gripper holds the load or books and arm detracts back. The double rod extend as it detected the colour to determine the level to sort on shelf. The wheels motor activate, causing the mechanism to move. The book sensor detects books on shelf. When no book detected, arm mechanism extend again and the gripper detract to release the book on shelf. The cycle repeated as long it detected next book on the book sensor. Thus, our programmed can be concluded succeeded. 


\section{Conclusion}

The conceptual design for the sorting and retrieval mobile robot system that can be used as assistant inside the library has been proposed. The mobile robot consists of the mobile platform, vertical pneumatic cylinder and horizontal gripper to arrange the books on the shelf and the PLC controller to control the whole operation process. The PLC program has been constructed and simulate in the simulation environment by utilizing OMRON CX programmer software.

In the future, this conceptual design will be materialized by prototype it and tested in the real time.

\section{Acknowledgment}

The author want to express appreciation to Unmanned and Autonomous Research Group, Centre of Excellence in Robotics and Industrial Automation and Universiti Teknikal Malaysia Melaka for sponsoring this project.

\section{References}

[1] Shukla, A. Upadhyay and A. K. Saxena, "Application of MRS Sorting Algorithm in Library", Automation International Journal of Engineering and Innovative Technology (IJEIT), vol. 2, Issue 1, (2012).

[2] P. S. Rajput, J. N. Gautam, "Automation and problems in their implementation: An investigation of special libraries in Indore, India”, International Journal of Library and Information Science, vol. 2, no. 7, (2010), pp. 143-147.

[3] S. P. Chavan, "Use of RFID Technology in Libraries", Online International Interdisciplinary Research Journal, \{Bi-Monthly\}, ISSN2249-9598, vol. II, Issue-IV, (2012).

[4] R. Ramos-Garijo, M. Prats, P. J. Sanz and A. P. Del Pobil, "An Autonomous Assistant Robot For Book Manipulation in a Library", IEEE. (2003).

[5] P. C. Patic and G. Gorghiu, "The Modeling And Simulation of a Robotic Arm", Scientific Bulletin of the Electrical Engineering Faculty, (2009).

[6] S. Tuntivivat and P. Prempraneerach, "Design and Construction and Motion Control of 6-Axis Robot Manipulator for Industrial Applications", The Second TSME International Conference on Mechanical Engineering , (2011) October, pp. 19-21, Krabi.

[7] H. Stefan, E. Bashar and F. Christos, "Axel Book Detection and Grasping in Library Scenario", 7th German Conference on Robotics, Proceedings of ROBOTIK 2012, (2012) May, Munich, Germany.

[8] X. Giralt, A.Hernansanz, A. Rodriguez and J.Amat, "Robotic Proximity Queries Library for Online Motion Planning Applications", New Developments in Robotics Automation and Control, InTech. (2008).

[9] G. Masseraa, S. Nolfia and A. Cangelos, "Evolving a simulated robotic arm able to grasp objects", Progress In Neural Processing, vol. 16, (2005), pp. 23.

[10] C. Pop and G. Mailat, "Automated Material Handling Systems (AMHS)in libraries and archives Automated Storage/retrieval and Return/sorting Systems", Recent Researches in Neural Networks, Fuzzy Systems, Evolutionary Computing and Automation, (2011).

[11] A. Butters, "Automating Library Processes Achieving success with Self-Service Loans \& Returns", Sybis, (2006).

[12] J. Suthakorn, S. Lee, Y. Zhou, R. Thomas, S. Choudhury and G. S. Chirikjian, "A Robotic Library System for an Off-Site Shelving Facility", Robotics and Automation, (2002).

[13] M. Z. A Rashid, T. A. Izzuddin, N. Abas, N. Hasim, F. A. Azis and M. S. M. Aras, "Control of Automatic Food Drive-Through System using Programmable Logic Controller (PLC)" , International Journal of u- and e- Service, Science and Technology, vol. 6, no. 4, (2013) August.

[14] N. Hasim, M. Z. A. Rashid, M. S. M. Aras, A. M. Kassim and S. S. Abdullah, "Development of fuzzy logic water bath temperature controller using MATLAB", Computing and Engineering (ICCSCE), 2012 IEEE International Conference on Control System, IEEE, (2012) November 23.

[15] H. N. M. Shah, M. Z. A. Rashid and T. Y. Tam, "Develop and Implementation of Autonomous Vision Based Mobile Robot Following Human", International Journal of Advanced Science and Technology, vol. 51, (2013) February. 
International Journal of u-and e-Services, Science and Technology Vol.7, No.4 (2014) 